\title{
Advancing the Structural Use of Earth-based Bricks: Addressing Key Challenges in the East African Context
}

\section{Esther Obonyo $^{1, *}$, Derrick Tate ${ }^{2}$, Vincent Sika ${ }^{3}$ and Mang Tia ${ }^{4}$}

1 Rinker School of Building Construction, University of Florida, PO Box 115703, Gainesville, FL 32611, USA

2 Mechanical Engineering Department, Texas Tech University, 7th and Boston, Lubbock, TX 79409, USA; E-Mail: d.tate@ttu.edu

3 Joinkit Technical Services, PO Box 102855-00101, Nairobi, Kenya; E-Mail: vwarima@yahoo.com

4 Department of Civil and Coastal Engineering, University of Florida, PO Box 116580, Gainesville, FL 32611, USA; E-Mail: tia@ce.ufl.edu

* Author to whom correspondence should be addressed; E-Mail: obonyo@ufl.edu; Tel.: +1-352-273-1161; Fax: +1-352-392-9606.

Received: 15 October 2010; in revised form: 4 November 2010 / Accepted: 15 November 2010 / Published: 19 November 2010

\begin{abstract}
The research discussed in this paper is a subset of a bigger, NSF funded research project that is directed at investigating the use of sustainable building materials. The deployment context for the research is the hot and humid climate using selected cases from the East African region. The overarching goal for the research is advancing the structural use of earth-based technologies. Significant strides can be made through developing strategies for countering the adverse factors that affect the structural performance of the resulting wall, especially ones related to moisture dynamics. The research was executed in two phases. The first phase was a two-day NSF supported workshop which was held in Tanzania in July 2009. It provided a forum for sharing best practices in earth-based building technologies and developing a research and development roadmap. The priority research areas were broadly classified as optimizing the physio-mechanical properties of earth as a building material and managing socio-cultural impediments. In the second phase of the research, the authors collaborated with researchers from East Africa to conduct experimental work on the optimization of physio-mechanical properties. The specific research issues that have been addressed are: (1) characterizing the chemical reactions that can be linked to deterioration triggered by hygrothermal loads based on the hot and humid context, and; (2) developing a prototype for a simpler, portable, affordable and viable
\end{abstract}


compressed brick production machine. The paper discusses the results from the characterization work that ultimately will be used to design bricks that have specific properties based on an understanding of how different stabilizers affect the hydration process. It also describes a cheaper, portable and more efficient prototype machine that has been developed as part of the follow-up research activities.

Keywords: earth-based bricks; physio-mechanical properties; durability; sustainability

\section{Introduction}

Earth architecture includes the use of adobe, cob, straw, and compressed earth blocks (CEBs). Within the North American context, although there are some examples of a few load bearing structures, earth-based bricks have generally been used as non-load bearing in-fill or cladding material. The most commonly used ones are fired bricks which raise concerns from a sustainability perspective. Recent innovations in the use of earth-based technologies in the US include the Super Adobe developed by Nader Khalili at the Cal-Earth Institute [1]. Buildings made with earth technologies are economical and environmentally friendly because of use of naturally occurring raw materials. They can also be used to promote energy efficiency through leveraging their thermal mass. This notwithstanding, there are some problems associated with the use of earth-based technologies.

Key concerns with the use of earth-based bricks include: (1) their low strength properties and (2) lack of durability in comparison to concrete blocks. There are also significant variations in the performance of earth-based bricks depending on soil variations, manufacturing methods, and climatic conditions [2]. Such factors have limited the structural use of earth-based bricks around the globe. Significant strides in advancing the structural use of earth-based bricks can be made through developing a best practice of how to manage the factors that affect the physio-mechanical performance of the resulting wall. Specific properties that have to be optimized include the strength of an individual earth brick, its geometry, the strength of the mortar, deformation characteristics of the bricks and the mortar, joint thickness, suction of the bricks, water retention of the mortar, brickwork bonding and workmanship [3].

Clearly, there are several issues that will have to be thoroughly investigated before the number of people using earth-based bricks can reach a critical mass. Many of these issues are being investigated by geographically dispersed researchers who have had limited, if any, opportunities for collaboration. As these issues impact on one another, there is a need for the researchers to work as a consortium to advance the structural use of earth-based technologies. The research discussed in this paper seeks to do just that. The initial task was forming a group consensus on fundamental research and development challenges, knowledge gaps, and research needs in the existing efforts directed at resolving such concerns. This was done through a two day, US-Tanzania workshop supported by the National Science Foundation (NSF). Two main discussion topics during the workshop were: (1) characterizing the general performance of earth-based bricks, and; (2) addressing key structural concerns with the use of earth-based bricks. The workshop culminated in in-depth deliberations that resulted in a definition of future research directions and the identification of opportunities for collaboration. As a follow-up to 
the workshop, the authors conducted some experimental work on two critical research issues for the East African context through collaborating with participants from Tanzania and Kenya: (1) characterizing the chemical reactions that can be linked to deterioration triggered by hygrothermal loads, and; (2) developing a prototype for a simpler, portable, affordable and viable compressed brick production machine.

\section{Research Approach}

The deployment context for the research focus is the hot and humid climate using selected cases from East Africa. Preliminary assessments of the quality of walling elements erected using earth-based bricks was done through a 3-month International Research Experience for Students program between May and July, 2008 in Tanzania. The deterioration of the brick walls was very apparent. Interviews with Tanzanian professionals identified two possible explanations for the deterioration of earth bricks: poor soil quality and breathability. There was also some belief that flaws in the brick production process could contribute to the problems. The authors also established that there was an erroneous assumption that the compressed bricks did not require external rendering. Earth-based bricks are not able to resist hygrothermal loads that can be expected in the hot and humid context. After identifying some possible explanations for the observed damage, the authors carried out an in-depth analysis through additional field visits and laboratory testing. A number of tests were carried out to determine whether or not the chemical properties of the soil could trigger deterioration in the bricks. The authors fabricated bricks in a controlled environment as a way of assessing ways of optimizing the bricks' physio-mechanical properties. General guidelines for stabilizing bricks that were adapted for the study are summarized in Table 1.

Table 1. Guidelines on using binders in bricks.

\begin{tabular}{|l|l|}
\hline Materials & Mixing \% \\
\hline Portland cement & Commonly used 6-10\%, recommended use is 4-15\% \\
\hline Lime & $6-12 \%$ \\
\hline Flyash & Fly ash-30\% \& Soil-70\% for making soil fly ash blocks \\
\hline Bentonite & $\begin{array}{l}\text { \% of sand is greater than 50 means we have to add 4-6\% } \\
\text { and less than 50 means 7-12\% }\end{array}$ \\
\hline Sodium silicate & 5\% \\
\hline Fiber & $1 \%$ of volume of soil \\
\hline
\end{tabular}

The hygrothermal performance of different types of brick units was further assessed through placing them in a climate-controlled chamber. The specimens were exposed to elevated temperature and humidity conditions based on 7-day cycles. They were then crushed to determine whether the exposure had resulted in significant changes in mechanical strength values. The hygrothermal loads were expected to trigger some chemical changes in the bricks. These chemical changes were characterized using the SEM and EDS analysis. This was accomplished through tracking changes in minerals that were known to be present.

During a second field visit in 2009, the brick production process was studied to determine whether there were quality control issues that could impact the quality of the bricks. The results of these 
investigations indicated that the problem with the bricks could be attributed to several factors. The soil that is available has much lower clay content than that predicted using traditional field testing methods. Additionally, the authors identified a key problem as the manual process of extracting the soil. Being very laborious, it inevitably leads to some top soil being used as input material. The top soil being rich in organic matter is not suitable for brick production. The authors also noted that man decisions were being made using a rule-of-thumb method that was not always accurate. For example, the field methods indicated that soil samples from some parts of Dar es Salaam in Tanzania had acceptable levels of clay content. When the same soil samples were assessed by geotechnical team at the Material Testing Lab in Gainesville, the clay content tended towards zero-suggesting that the stabilization strategy that was being used in the field was not appropriate.

Of all the process-related issues that were identified, problems related to the use of the manual brick fabricating machine emerged as a critical area of need. The authors experimented with the different ways of addressing the inefficiencies associated with the use of the machine. The key objective for this aspect of the research was developing a simpler, portable, affordable and viable machine. After assessing the existing machine, the authors designed a mould box with a simple ejection mechanism and a hydraulic jack customized to give the compression load required for moulding the bricks. Other factors that were considered were the strength of fabrication plates and hydraulic jack tonnage.

\section{Critical Research Issues for the East African Context: Key Findings from the NSF US-Tanzania 2009 Workshop}

In the deliberations at the NSF US-Tanzania 2009 Workshop, participants addressed variations in the strength, response to humidity, water resistance, constructability and thermal resistance performance of earth-based bricks. As indicated in a preceding section, some of the variation problems can be attributed to quality-control issues. The definition of a robust quality strategy was identified as one of the ways of optimizing the performance of earth-based technologies. Specific elements of a good quality-control strategy include establishing measures for ensuring compliance with existing standards, setting up best practices for each country, and offering training and education to help people to appreciate the value of high quality. Training and education should be coupled with regulatory or professionally-accredited certification for on-the-job training. Participation in these activities should count for Continuing Professional Development (CPD) credits. This training should specifically target designers, contractors, and builders as well as building inspectors.

The workshop participants also indicated that existing research institutions could make a significant contribution to addressing specific quality control problems such as the appropriate use of stabilizers and mortars. Researchers and developers in developing countries are often handicapped by the lack of research funding. In addition to wanting the government to promote research in earth-based technologies, there was also some interest in having regulatory authorities provide seed money for demonstration projects for implementing research outcomes.

The participants came up with specific performance issues that needed to be addressed through further research. For new buildings, most of these emphasized strategies that ensure that it fulfills functional requirements. For existing buildings, energy-saving retrofits and conservation of cultural heritage were identified as key issues. Specific topics that were identified as not having been 
sufficiently addressed with respect to earth-based bricks were: (1) Safety and the resilience of the resulting structures especially with respect to natural disasters; (2) Durability of the resulting structures; (3) Achieving the right level of air tightness (breathable walls); (4) Securing adequate levels of thermal comfort for occupants, and; (5) Optimizing the hygrothermal performance of walls.

Although there is great value in developing universal guidelines for earth-based technologies, there are several regional specific issues that have to be addressed uniquely. The participants identified examples of opportunities for embracing global diversity. In general, there was confidence that sharing lessons learned would be the best way of managing quality-related problems. However, this has to be done cautiously to encourage the use of what is available locally and the incorporation vernacular architecture. A key focus for sharing lessons learned should be identifying opportunities for improvement. The lack of sufficient documentation on earth-based technologies was identified as a critical area of need that is hampering the sharing of knowledge especially in developing countries within Sub-Saharan Africa.

The participants also considered several topics linked to strategies for enhancing the durability and compressive strength properties of earth-based bricks. Specific things discussed by the participants included identifying key dependent and independent variables for brick production and also clarifying expectation for mechanization versus using manual labor in earthen construction. Key dependent and independent variables for brick production as identified by the participants have been summarized in Table 2.

Table 2. Key dependent and independent variables.

\begin{tabular}{|c|c|}
\hline Dependent Variables & Independent Variables \\
\hline $\begin{array}{l}\text { - } \quad \text { Compressive strength } \\
\text { - } \quad \text { Shear strength } \\
\text { - } \quad \text { Porosity/texture } \\
\text { - } \quad \text { Tensile strength } \\
\text { - } \quad \text { Durability, finish, } \\
\text { adhesion } \\
\text { - } \quad \text { Permeability, water } \\
\text { absorption, swelling }\end{array}$ & $\begin{array}{l}\text { - } \quad \text { Equipment and tools } \\
\text { - } \quad \text { Mix ratios, time, condition (covered and } \\
\text { - } \quad \text { Mixing methods, distribution of grains } \\
\text { - } \quad \text { Method of compression: tamping, mechanical, } \\
\text { - } \quad \text { vibration } \\
\text { - } \quad \text { Stabilizing agents, e.g., cements, lime, pozzolana } \\
\text { - } \quad \text { Curing methods, weather condition, temperature } \\
\text { - } \quad \text { Curing time } \\
\text { - } \quad \text { Training, skills } \\
\text { - } \text { Quality control } \\
\text { - Different kinds of soil, locally available: } \\
\text { For example, simple clay, silty clay (absorbs } \\
\text { more water, plastic), slay mixed with organic } \\
\text { matter (“black cotton”) and clay mixed with sand }\end{array}$ \\
\hline
\end{tabular}

The participants identified several factors that need to be considered in choosing between mechanized and manual brick production equipment. From a structural perspective, mechanization would eliminate many of the flaws in the production process that ultimately result in bricks that have variations in performance. Mechanized brick production gives one better control over the 
manufacturing process resulting in units that are of good quality in terms of uniformity and strength. In addition, the use of mechanized equipment increases the productivity in terms of number and size of units produced. However, before one deploys the mechanized approach, socio-economic factors in the deployment context must be considered. In developing economies such as Kenya and Tanzania, it would be difficult for most people to raise the initial capital that would be required to purchase mechanized machines. The manually operated equipment being less expensive will always be the only option for most people. Its use has also been historically linked to job creation as it involves using at least 2 to 3 laborers throughout the operation. There is, however a strong argument in favor or mechanized equipment that can counter concerns over possible job losses. If the mechanized machines are deployed within the context of a factory where brick production is a much large scale, it would provide employment opportunities for more people than the ones who are currently hired to power manually operated brick-making machines. The production costs at the factory would also have to be tightly controlled to off-set material transportation costs. In the current practice, the relatively much smaller manually-operated machine can be used in congested sites, thus eliminating the transportation costs associated with using bulky equipment that in may have to be used off-site.

\section{Main Findings from Follow-up Experimental Work}

The results from the additional experiments done after the workshop are summarized in Table 3. From these findings, it is clear that the use of the three different stabilization strategies (cement, cement-lime, cement fiber) did not results in any significance differences in the performance of the bricks in terms of properties such as porosity, density and compressive strength. This was also true for thermal properties (relative heat capacity and thermal conductivity) as well as moisture properties (water vapor diffusion, water absorption and diffusion and water absorption coefficient). When different types of bricks were aged through exposure to elevated moisture and temperature conditions over a 7-day period, the compressive strength values dropped significantly when just cement or cement-lime was used in mix (48.19 and $46.20 \%$ respectively). The soil-cement-fiber bricks registered the highest residual strength values (approximating 87\% per cent). This suggests that inclusion of natural fibers in low-cost construction materials can potentially enhance the resulting composites' performance with respect to hygrothermal loads.

The authors used electron microscopical techniques to elucidate preliminary data on the chemical changes that can be linked to exposure-related deterioration. The bricks in this research are examples of cementitious materials. The efforts to characterize the chemical reactions are therefore directed at addressing how the organic components in the cementitious system affect hydration. Despite cementitious materials constituting one of the most commonly used construction materials, there are still significant knowledge gaps concerning a detailed understanding of the mechanism that impacts their performance [4]. Non-cementitious components can be expected to drown the signal from the cementitious component. This makes it difficult to capture accurate quantitative date on the evolution of microstructure during hydration. This knowledge is essential for designing and developing cementitious materials with specific properties. Such efforts are also impeded by difficulties in linking observed differences to either desirable or undesirable physio-mechanical properties that would be indicative of the materials' expected performance during service conditions. 
Table 3. Mechanical and Physical Properties.

\begin{tabular}{|l|c|c|c|c|c|c|}
\hline Type of Brick & Porosity & $\begin{array}{c}\text { Density } \\
\mathbf{( K g / \mathbf { m } ^ { 3 } )}\end{array}$ & $\begin{array}{c}\mathbf{2 8} \text { Day } \\
\text { compressive } \\
\text { strength (psi) }\end{array}$ & $\begin{array}{c}\mathbf{2 8} \text { day Water } \\
\text { absorption } \\
\text { coefficient value }\end{array}$ & $\begin{array}{c}\text { Residual } \\
\text { Strength* } \\
\mathbf{( \% )}\end{array}$ & $\begin{array}{c}\text { Thermal } \\
\text { conductivity } \\
\text { (W/mK) }\end{array}$ \\
\hline Soil-Cement & 0.14 & 1,054 & 1,100 & 0.093 & 48.19 & 0.79 \\
\hline Soil-cement-lime & 0.12 & 1,144 & 1,200 & 0.089 & 46.20 & 0.75 \\
\hline Soil-cement-fiber & 0.16 & 1,058 & 1,150 & 0.092 & 87.00 & 0.79 \\
\hline
\end{tabular}

* After 7-day exposure to elevated moisture and temperature conditions-indicates resistance to hygrothermal loads.

Table 4 summarizes the chemical characterization showing changes after samples have been aged through being immersed in water and exposed to $100{ }^{\circ} \mathrm{C}$ temperatures in an oven for 7 days. Based on this initial data, it is possible to identify some of the key changes that were captured. Focusing on the Carbon, Oxygen, Silica and Calcium (linked to hydration), a few things can be observed. In the soil-cement unit, there is no significant change during the preliminary investigations. The inclusion of lime triggers chemical reactions that increase Silica while decreasing Calcium. The chemical reactions that occur when fiber is included in the mix increases the Carbon content while decreasing the Oxygen, Silica and Calcium content. Additional work is being done to link these changes to specific physio-chemical properties.

As indicated earlier, addressing the inefficiencies in the use of the machine was a key research issue. The authors experimented with different options. In the final prototype, the mould was designed to match the existing compressed earth brick sizes $(300 \mathrm{~mm} \times 150 \mathrm{~mm} \times 140 \mathrm{~mm}$ ). For the ejection mechanism, although bottom-top reciprocating, leg-operated ejector was initially identified as a potential strategy, its use was discarded during the evaluation of the of machine performance as it resulted in the use of excessive force during the ejection process. The authors reverted to use of a hydraulic jack for compression as an ejector as its use proved to be more convenient and required less effort. The use of steel for the mould plates factored the materials' impact on the overall weight of the machine. Through the authors' assessment limiting the total weight of the machine to $30 \mathrm{~kg}$ ensured portability as this weight can easily be transported using a bicycle, wheelbarrow or handcart. The total weight of the prototype was $25 \mathrm{~kg}$ (28 kg inclusive of the hydraulic jack). Figure 1 shows the final prototype.

The authors determined the depth of fill and the hydraulic jack tonnage concurrently. These parameters are generally affected by the strength of the mould box steel plates. After several tests, a 10 tonne jack and a fill height of 9” from the rim were identified as the optimal ones for the prototype. The 9" height from the lid may need to be adjusted during the moulding process depending on the type of soil and the desired compression strength. This can easily achieved through adjusting the screw on top of the jack and using jacks of varied capacities. 
Table 4. EDS results.

\begin{tabular}{|c|c|c|c|c|c|}
\hline \multirow{2}{*}{ Types of Sample } & \multirow{2}{*}{ Chemical } & \multicolumn{2}{|c|}{ Original Brick Sample } & \multicolumn{2}{|c|}{ Aged Samples } \\
\hline & & Element (\%) & Atomic (\%) & Element (\%) & Atomic (\%) \\
\hline \multirow{8}{*}{ Soil Cement } & $\mathrm{C}$ & 9.1 & 14.8 & 10.2 & 16.3 \\
\hline & $\mathrm{O}$ & 51.7 & 62.8 & 51.3 & 61.5 \\
\hline & $\mathrm{Mg}$ & 1.6 & 1.2 & 0.4 & 0.3 \\
\hline & $\mathrm{Al}$ & 3.7 & 2.6 & 5.4 & 3.8 \\
\hline & $\mathrm{Si}$ & 11.2 & 7.8 & 13.6 & 9.3 \\
\hline & $\mathrm{Ca}$ & 19.7 & 9.6 & 15.4 & 7.4 \\
\hline & $\mathrm{Ti}$ & 0.3 & 0.1 & 0.6 & 0.2 \\
\hline & $\mathrm{Fe}$ & 2.1 & 0.7 & 2.4 & 0.8 \\
\hline \multirow{7}{*}{ Soil Cement lime } & $\mathrm{C}$ & 6.8 & 11.0 & 11.1 & 17.3 \\
\hline & $\mathrm{O}$ & 50.3 & 63.8 & 52.3 & 61.5 \\
\hline & $\mathrm{Al}$ & 2.4 & 1.8 & 4.3 & 3.0 \\
\hline & $\mathrm{Si}$ & 9.9 & 6.8 & 15.9 & 10.5 \\
\hline & $S$ & 0.4 & 0.3 & 0.6 & 0.4 \\
\hline & $\mathrm{Ca}$ & 25.7 & 13.7 & 13.3 & 6.3 \\
\hline & $\mathrm{Fe}$ & 2.2 & 0.8 & 1.8 & 0.6 \\
\hline \multirow{8}{*}{ Soil Cement Fiber } & $\mathrm{C}$ & 14.7 & 21.6 & 17.7 & 26.5 \\
\hline & $\mathrm{O}$ & 54.2 & 59.9 & 46.5 & 53.5 \\
\hline & $\mathrm{Mg}$ & 0.1 & 0.1 & 0.1 & 0.1 \\
\hline & $\mathrm{Al}$ & 4.3 & 2.8 & 4.3 & 3.0 \\
\hline & $\mathrm{Si}$ & 21.1 & 13.3 & 14.0 & 9.3 \\
\hline & $\mathrm{Ca}$ & 3.7 & 1.6 & 12.8 & 5.9 \\
\hline & $\mathrm{Ti}$ & 0.3 & 0.1 & 0.6 & 0.2 \\
\hline & $\mathrm{Fe}$ & 1.3 & 0.4 & 3.0 & 1.0 \\
\hline
\end{tabular}

Figure 1. A prototype for an improved compressed brick machine.

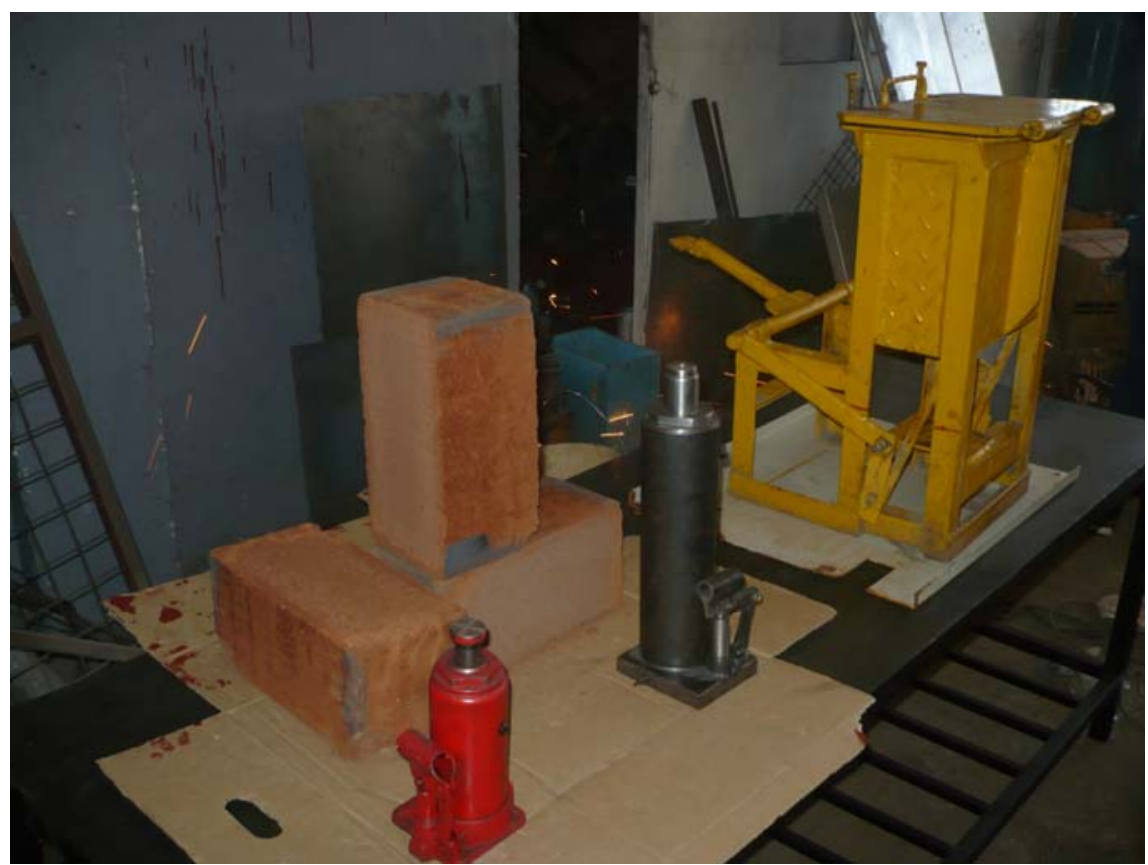


During the evaluation of the prototype, the authors produced exemplary bricks and had them evaluated by government-operated Building Material Testing and Research laboratories in Nairobi. It is important to bear in mind that the laboratory usually provides results indicating either a "pass" or "failure" with respect to approval for use in building structures in Kenya. The bricks produced using the prototype passed the approval test. Other physio-mechanical properties were tested by the authors at the fabrication yard. The average water absorption rate was $11.45 \%$. The bricks had an average weight of $8.395 \mathrm{~kg}$ and an average density of $1,335 \mathrm{~kg} / \mathrm{m}^{3}$.

As indicated earlier, the authors also wanted to make the machine more affordable. A commercially compressed brick machine is priced at Kenya Shillings 111,360 (about US \$ 9,000). The prototype would not cost more than Kenya Shillings 40,000 (US \$ 3,200). In addition to the cost savings, the machine also results in faster production rate. With the existing design for the prototype, the production rate is 25 bricks an hour. This can be easily doubled through providing an additional compartment in the mould. Using the customized hydraulic jack designed by the authors, instead of using two operators, the brick production can be done using one operator. Another advantage with the prototype is that it can be used by an operator with limited mobility in lower parts of the body. Further work is still being done to refine the prototype.

\section{Conclusion and Further Work}

Building materials can be classified rated as best for the environment if they contain the following characteristics: (1) materials made with salvaged, recycled, or agricultural waste content; (2) materials that conserve natural resources; (3) materials that avoid toxic or other emissions; (4) materials that save energy or water; (5) materials that contribute to a safe, healthy, built environment [5]. There has been a specific concern over greenhouse gases (GHGs) that has resulted in several efforts being directed towards reducing their release into the atmosphere. In Condition 2 of LP Hedelberg's movement, The Natural Step, there is a caution against the use of man-made materials that take a long time to decompose where dioxins are explicitly identified as examples of compounds that will almost never be broken down by nature. Given that building materials are largely inert, key areas of concern from an ecological perspective are ensuring that the manufacturing is done with the least impact and also designing the products for easy disassembly and recycling [6]. An assessment based on an ecological perspective makes earth-based building materials good options to explore as a way of minimizing the adverse effects of buildings on the environment.

However, it is important to bear in mind that ecological concerns comprise just one aspect of greening the built environment. The definition of what would constitute a sustainable building system is much broader. For the discussion in this paper, the authors have linked the performance goals to the efforts directed at delivering "high performance building” systems. In 2008, the US building enclosure community launched a formal initiative directed at delivering high-performance buildings. This initiative underscored the linkages between energy efficiency, durability and the quality of the indoor environment [7]. A "high performance building" here refers to the Energy Policy Act of 2005 [8] description of: "a building that integrates and optimizes all major high performance building attributes, including energy efficiency, durability, life cycle performance, and occupant productivity.” Clearly, optimizing the structural performance of building materials constitutes a key aspect of realizing a high 
performance building. This paper has identified some of the key research issues that would have to be addressed before earth-based construction techniques can truly satisfy the requirements for a high-performance building system. These were based on the deliberations of the NSF sponsored workshop. Specific issues that were identified as priority research areas are as outlined below:

- Thermal and Moisture Properties of Earthen Construction: Not much information is known in this area. More research needs to be done, especially focusing on how these materials can be optimized to withstand hygrothermal loads.

- Durability Issues: How long will an earth-based brick house last under different environmental conditions? Additional research can be done in this area to showcase earthen construction as being comparable to concrete or any other conventional material with respect to withstanding the test of time.

- Optimizing the production process, for example, making improvements to the manually operated compressed brick production machine as a way of minimizing variations in performance.

- Acoustical Properties: Although earth is known to have good acoustic properties (good sound absorption and insulation), this benefit has not been exploited much in earthen construction.

- Safety Issues: Earth-based bricks are known to have the ability to absorb bullets well. Houses made with earth-based bricks should be fairly safe to live in with respect to resistance to bullets and explosions. It may be possible to obtain funding from agencies such as DTRA (Defense Threat Reduction Agency) to study the safety of this type of house.

- Mortar Issues: When would mortar be needed and when would it be not necessary? Additional research can be conducted to prevent building failure that can be expected should people omit mortar where it is needed.

- Socio-Cultural Perception: There is a widespread misconception from the general public and government officials that earth-based bricks are cheap construction materials for poor people. They are therefore avoided as low quality materials. Efforts should be made to educate the general public about the capability and quality of this material, so that it could be effectively utilized to reap its full potential benefits.

Based on these recommendations, the authors conducted some experimental work on two critical research issues for the East African context through collaborating with participants from Tanzania and Kenya: (1) characterizing the chemical reactions that can be linked to deterioration triggered by hygrothermal loads, and; (2) developing a prototype for a simpler, portable, affordable and viable compressed brick production machine. The results in the preceding section illustrate the characterization work that is being done to generate data on chemical changes that can be expected depending on the stabilization strategy being used. This evolving data contributed to efforts directed at an understanding on how different factors (including the use of organic material as input material) affects the hydration process in cementitious systems. This information will ultimately be used to design bricks with specific properties. The authors are doing further work in this area. The discussion also presented a prototype system for an improved compressed brick production machine. The prototype achieved its initial goals of being cheaper, portable and more efficient without compromising the physio-mechanical properties of the resulting bricks. The authors are experimenting with additional refinements to the system. These include (1) increasing the number of moulds per 
machine from one to further increase productivity; (2) Designing faster ejection system; (3) Incorporating an built-in pressure gauge to monitor compression loads during brick production, and; (4) Designing a flexible mould that can support the production of interlocking bricks.

\section{Acknowledgements}

The work presented in this paper was supported by National Science Foundation (NSF) funding through CMMI-SMM Award No. 0914372.

\section{References and Notes}

1. Hammet, M. Basic Guide to Brickwork Mortars; The Brick Development Association: London, UK, 1988.

2. Eco-Dome: "Moon Cocoon"; Cal-Earth, The California Institute of Earth Art and Architecture: Hesperia, CA, USA; Available online: http://calearth.org/building-designs/eco-dome.html (accessed on 15 October 2008).

3. Prinster, M.; Warden, B. Understanding Stabilized Earth Construction: Building with Strength in Mind; School of Architecture and Urban Design, University of Kansas: Lawrence, KS, USA, 2005; Available online: www.kubuildingtech.org (accessed on 18 September 2008).

4. Scrivener, K.L. Backscattered electron imaging of cementitious microstructures: Understanding and quantification. Cement Concrete Composites 2004, 26, 935-945.

5. Lazarus, N. Potential for Reducing the Environmental Impact of Construction Materials; Commissioned by Bioregional Development Group: Surrey, UK, 2005; Available online: http://www.bioregional.com/files/publications/Z-squaredImpactMaterials_Jan05.pdf (accessed on 4 June 2009).

6. Kibert, C. Sustainable construction. In Polymers in Construction; Akovali, G., Ed.; Rapra Technology Limited: Shawbury, UK, 2005; pp. 308-324.

7. Bomberg. M.; Onysko, D. Energy Efficiency and Durability of Buildings at the Crossroads; Available online: http://www.aia.org/aiaucmp/groups/ek_members/documents/pdf/aiap072715. pdf (accessed on 1 July 2009).

8. Energy Policy Act of 2005 Public Law 109-58-AUG. 8, 2009; EPA: Washington, DC, USA, 2005; Available online: http://www.epa.gov/oust/fedlaws/publ_109-058.pdf (accessed on 1 July 2009).

(C) 2010 by the authors; licensee MDPI, Basel, Switzerland. This article is an open access article distributed under the terms and conditions of the Creative Commons Attribution license (http://creativecommons.org/licenses/by/3.0/). 